
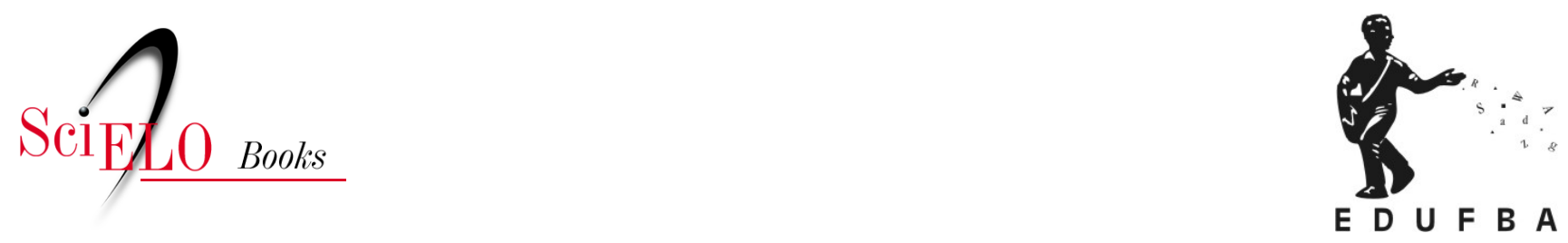

\title{
Pensar por biografias
}

\author{
Priscilla Peixoto
}

\section{SciELO Books / SciELO Livros / SciELO Libros}

PEIXOTO, P. Pensar por biografias. In: JACQUES, P.B., and PEREIRA, M.S., comps. Nebulosas do pensamento urbanístico: tomo I-modos de pensar [online]. Salvador: EDUFBA, 2018, pp. 70-97. ISBN 978-85-232-2032-7. https://doi.org/10.7476/9788523220327.0004.

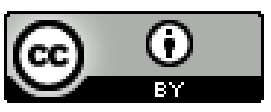

All the contents of this work, except where otherwise noted, is licensed under a Creative Commons Attribution 4.0 International license.

Todo o conteúdo deste trabalho, exceto quando houver ressalva, é publicado sob a licença Creative Commons Atribição 4.0. 
PENSA R PO R 


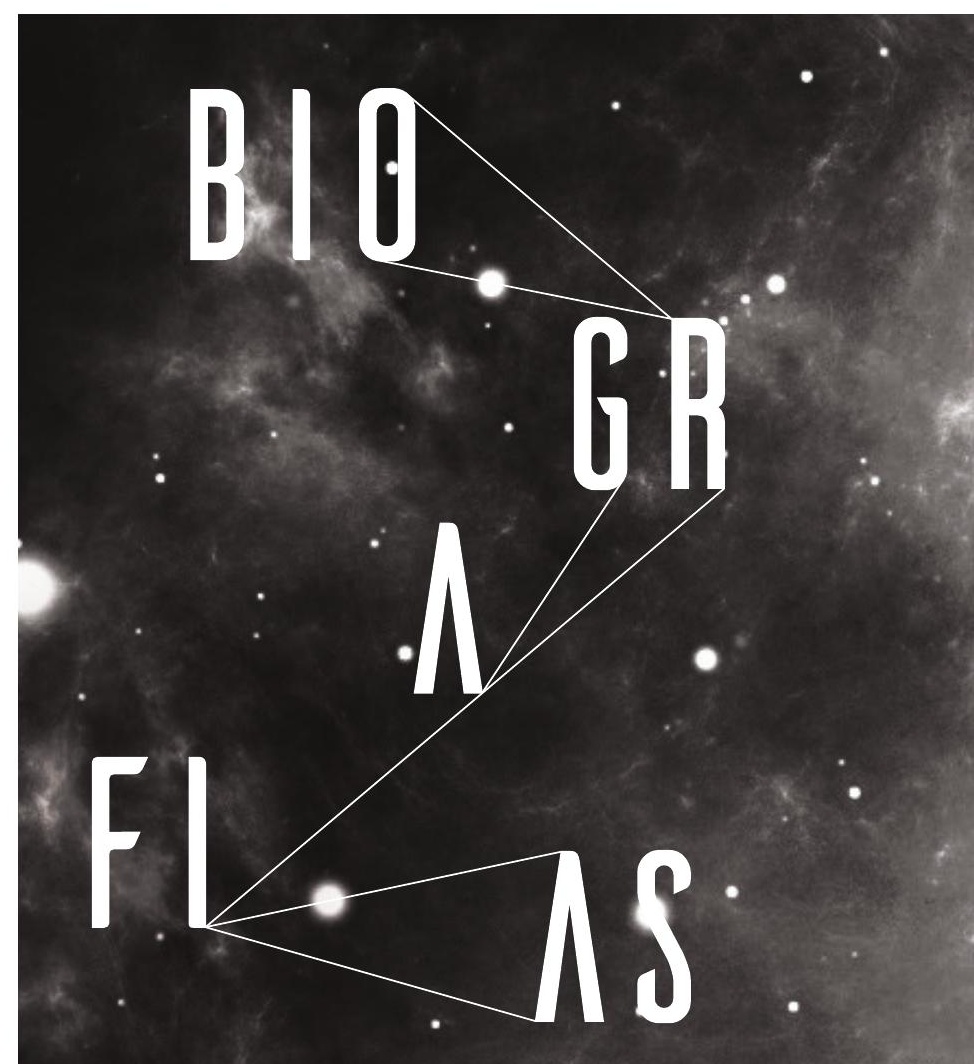




$$
\begin{gathered}
\text { PENSA } \\
\text { P O R } \\
\text { BI O G B A I A S }
\end{gathered}
$$

Notas sobre modos de romper modelos, atravessar fronteiras e ativar o passado ${ }^{1}$

$$
\begin{aligned}
& P \text { R I S C I L L } ~ \\
& P E I X O T O
\end{aligned}
$$


nquanto gênero literário, a biografia resiste de Plutarco a Donatella Calabi, somando odes e críticas imensas e apaixonadas ao longo de quase 2 mil anos de história. Desenvolver essa questão em um breve artigo - como o proposto para esse capítulo - é, portanto, um grande desafio. Afinal, tem-se o risco eminente de recair sobre aspectos fartamente já estudados.

Visando minimizar tamanha imprudência, busca-se, aqui, delimitar um recorte mais circunscrito: o pensar por biografias nos estudos de história do urbanismo. Dito de outra forma, tematizaremos a valorização recente das narrativas que interpretam as condições de possibilidades individuais na produção de uma cultura que interroga e projeta as diferentes dimensões da vida em cidades.

Assim, este capítulo é organizado em três partes. Primeiramente, será abordada a escrita da história do urbanismo em dois importantes seminários no Brasil. Neste cenário, será destacado o papel que os estudos biográficos passaram a desempenhar. Na sequência, interrogaremos os motivos que, mesmo de forma latente, orientam essa abordagem. Por fim, serão visitados alguns autores que não se detiveram sobre a escrita da história do urbanismo especificamente, mas que trazem insumos para as questões desenvolvidas ao longo deste percurso. 


\section{EsTABELECENDO UM PONTO DE PARTIDA}

Como já mencionado, antes de abordarmos diretamente os estudos biográficos, enfocamos uma questão mais ampla: como os modos de narrar o urbanismo - a historiografia do urbanismo - vêm sendo tematizados nos últimos anos no Brasil?

Para ilustrar essa questão, apresentamos dois conjuntos de trabalhos separados no tempo por cerca de 20 anos. O primeiro, três artigos do II Seminário de História das Cidades e do Urbanismo (SHCU), de 1993. O segundo, um conjunto de artigos produzidos para os três primeiros Seminários Urbanismo e Urbanistas no Brasil (SUUB), entre 2013 e 2017.

O SHCU é um evento bienal "criado por iniciativa do Programa de Pós-graduação em Arquitetura e Urbanismo da Universidade Federal da Bahia, [...] [que] vem sendo realizado [...], desde 1990". (APRESENTAÇÃO..., 2016) Ele tem por objetivo contribuir para o conhecimento das cidades e do urbanismo a partir da história.

Ao analisar os anais do evento, observa-se que, na sua segunda edição, de 1993, houve um esforço de definir o corpus do próprio seminário. Isso se torna evidente ao observarmos que alguns trabalhos colocaram questões como: qual seria a especificidade dos objetos de estudo da história urbana?

Apesar dos títulos nem sempre apresentarem essa questão de forma evidente, três trabalhos merecem nossa atenção: "História urbana: história na cidade?", de Raquel Rolnik; "Permanência e ruptura no estudo das cidades", de Maria Stella Bresciani; e "A cidade e o urbano como espaço-tempo", de Milton Santos.

Nota-se que a comunicação de Raquel Rolnik é breve. No entanto, em sua argumentação, a autora busca lançar luzes sobre quais seriam os objetos da história urbana. Ela se pergunta: seria o território? O espaço? A vida social?

$\mathrm{Na}$ tentativa de construção de uma resposta aos seus próprios

74 questionamentos, percebe-se que Rolnik desenvolve uma clara filiação 
ao estruturalismo, sobretudo por citar diretamente o entendimento que Fernand Braudel elaborou sobre história social. Justamente por isso, Rolnik evidencia um entendimento de história urbana como aquela destinada a "dar a ver" os processos na longa duração, dos aspectos que mudam muito lentamente. Evidencia, portanto, os aspectos mais perenes desses processos, suas estruturas. É ela quem escreve:

A questão fundamental para os historiadores urbanos [...] seria o significado dos processos de territorialização e desterritorialização na história e sua relação com o processo mais global e genérico que acontece na vida social, econômica e política dos povos. (ROLNIK, 1993, p. 27-29)

O trabalho desenvolvido por Maria Stella Bresciani também se inicia pela "difícil definição de um objeto", para utilizarmos as palavras da própria autora. Aprofundando ainda mais o interesse já demonstrado por Rolnik, Bresciani apresenta como possibilidades para a história urbana tanto a tematização da dimensão material das cidades quanto a de uma história que toma por objeto as disputas conceituais, ideológicas e de formas de ação nas cidades. Apesar de enunciar essas duas correntes, Bresciani mostra-se claramente engajada na segunda.

O trabalho de Bresciani ainda possui mais desdobramentos. No entanto, é curioso notar que, como no caso de Rolnik, ao definir seu objeto, Bresciani também dava mostras de sua filiação no que concerne a suas práticas historiográficas, ou seja, a maneira como escolheu escrever história.

No caso de Bresciani, além da já mencionada inclinação à história das ideias, nota-se também ênfase em uma narrativa que faz emergir as dualidades, como as conhecidas oposições entre campo e cidade, arte e técnica, classe burguesa e proletariado.

Por fim, deve-se se destacar também o trabalho do geógrafo Milton Santos - na época, possivelmente o nome de maior envergadura presente no seminário. Em seu trabalho, "A cidade e o urbano como espaço-tempo", é possível observar a emergência ainda de uma terceira questão relativa ao objeto da história urbana e, por conseguinte, 
das práticas de escrita da história. Seu texto, também curto, faz um balanço do que foi debatido em uma das mesas daquele seminário.

Nesse balanço, ele entende que o objeto da história urbana é aquele mesmo enunciado por Rolnik e que toma por objeto os processos de urbanização na longa duração. No entanto, a questão que emerge em seu texto é justamente a insuficiência dessa forma de história para dar a ver a especificidade dos diferentes contextos, aquilo que muda de uma cidade a outra. Contra a história urbana - para ele, uma espécie de "história universal" -, ele propõe a história das cidades. É ele quem escreve:

$\mathrm{Na}$ realidade, duas coisas estão sendo confundidas gratuitamente, graciosamente, alegremente: a cidade e o urbano. Há duas coisas que se pode fazer separadamente ou conjuntamente: a história da cidade e a história do urbano. O urbano é frequentemente o abstrato, o geral, o externo. A cidade é o particular, o concreto, o interno. Não há o que confundir. (SANTOS, 1993, p. 242-243)

Quase 20 anos após essa edição do SHCU, o campo dos historiadores do urbanismo pôde contar com outro fórum de discussões. Tratou-se da criação do SUUB, em 2013. Este segundo evento da área não silencia ou desarticula a organização do primeiro, apenas torna mais específica a abordagem que aglutina suas pesquisas, as biografias de urbanistas. Esse aspecto já era sublinhado no anuncio do seminário, em seu sítio na internet:

Seminário sobre os profissionais urbanistas (brasileiros e estrangeiros) que atuaram no Brasil nos séculos XIX e XX. Neste evento os debates direcionam-se à documentação pesquisada, com ênfase em abordagens teórico-metodológicas, as narrativas desenvolvidas, as categorias analíticas e os debates profissionais sobre a construção e institucionalização do urbanismo como campo disciplinar e prática profissional. Interessa a atuação de profissionais nos setores públicos de urbanismo, no ensino, a produção intelectual em artigos, livros e revistas, os planos urbanísticos e a participação no planejamento urbano e regional. (APRESENTAC̣ÃO..., 2013) 
Atualmente, este seminário já está em sua terceira edição e, de fato, tornou-se um importante local de estudo do urbanismo no Brasil a partir de biografias intelectuais dos urbanistas. Seus anais dão conta de um importante panorama da maneira como o urbanismo vem sendo praticado no país, permitindo-nos elaborar comparações e interpretar os limites das diferentes culturas urbanísticas.

No entanto, mais do que analisar de maneira pormenorizada as comunicações desse seminário, interesso-me aqui em compará-las àqueles trabalhos que buscaram estabelecer o escopo das pesquisas do SHCU, quase 20 anos antes.

O primeiro aspecto que nos chama atenção é, sem dúvida, uma mudança radical nas "escalas de análise". (LEPETIT, 1998) Se, no conjunto de trabalhos apresentados em 1992, no SHCU, privilegiavam-se as análises na longa e média duração com sua atenção às estruturas, aos invariantes culturais e aos processos, bem como às mentalidades e aos grupos sociais, o conjunto dos trabalhos do SUUB demonstra, por outro lado, uma atenção mais fina à curta duração na qual indivíduos, suas práticas e suas culturas específicas são o foco das narrativas.

O segundo aspecto a ser sublinhado é a virtualidade do próprio tema inicial do SHCU. Chamando-se Seminário da História das Cidades e do Urbanismo, é curioso notar que o último termo - "do urbanismo" - tenha sido substituído por um correlato chamado "urbano". Como se pôde observar nas comunicações que apresentamos, os debates se concentraram, de fato, na história urbana e das cidades, na qual se sublinhou ora o estudo dos processos de construção das cidades, ora o caráter plural de seus construtores. Em ambos os casos, a especificidade do urbanismo é ou rebaixada, ou silenciada ${ }^{3}$.

No SUUB, o panorama é, de fato, outro. No editorial da revista que publicou os primeiros anais do encontro, podemos observar justamente os contornos precisos desse objeto:

O interesse no estudo dos profissionais passa fundamentalmente pela possibilidade de compreensão dos processos de circulação das ideias urbanísticas e sobre os problemas 
e desafios urbanos de um modo geral. Foram (e são) essas ideias que estruturaram (estruturam) os debates sobre melhoramentos urbanos e planos urbanísticos, planos diretores, planos regionais, o desenvolvimento social-urbano a construção-institucionalização do urbanismo no Brasil, especialmente a institucionalização do campo disciplinar do urbanismo como prática profissional de atuação nas administrações municipais para soluções dos 'problemas urbanos': neste caso especialmente pela atuação de engenheiros e urbanistas. Ao mesmo tempo, essas mesmas ideias têm papel importante, mesmo fora do campo dos especialistas, ao instruir paulatinamente as formas de apreensão e entendimento do urbano. (FARIA; CERASOLI, 2013, p. 1)

Assim, ao contrastarmos as posições dos artigos do II SHCU e as dos três primeiros SUUB, percebe-se uma mudança do ponto de vista teórico-metodológico que orienta as pesquisas de cada seminário. De certa forma, a opção pelo caminho do estudo de biografias parece dar forma a parte da crítica realizada por Milton Santos à história urbana, pois ela justamente traz a especificidade das práticas de construção de cidades em situações específicas, balizadas pelo olhar de um dos seus atores.

Nesse ponto, nota-se que o encaminhamento dado pelos trabalhos do SUUB não responde a todos os matizes da crítica do geógrafo, pois ela está mais centrada na potência construtiva das práticas dos urbanistas enquanto saber especializado, e não de todos aqueles envolvidos nas construções das cidades. Contudo, o que gostaríamos de sublinhar aqui é justamente a escolha do estudo do urbanismo a partir da biografia dos urbanistas e o objetivo que ele traz latente consigo: a possibilidade de olhar o caso particular e, com isso, demonstrar a pluralidade desse "saber-fazer".

No entanto, não queremos dar aqui a falsa impressão de que o estudo por biografias é alguma espécie de "evolução" em relação ao olhar para a escala da longa duração. De fato, não é essa a questão - tanto que autores que estavam presentes nos primeiros SHCU, como Maria

78 Stella Bresciani, também fazem parte dos autores do SUUB. 
Acredita-se aqui que a escrita da história se beneficia de um certo jogo de escalas. (REVEL, 1998) Escolher olhar ora para curta-duração, ora para média-duração e ora para a longa-duração deve ser uma espécie de calibragem que as hipóteses e os objetivos de cada pesquisa é que irão determinar.

Afinal, como bem já havia apresentado o próprio Fernand Braudel (2009, p. 44), aquele mesmo citado por Rolnik, o tempo pode se desdobrar em diferentes temporalidades - ritmos, para dizermos de maneira mais simples $-{ }^{4}$ tais como: o tempo curto do evento e dos indivíduos; o tempo cíclico da conjuntura, das mentalidades e das representações; e o tempo dilatado das estruturas sociais e econômicas, dos invariantes culturais e das mudanças geográficas.

De certa forma, é a uma conclusão semelhante a que os envolvidos no SUUB chegam ao final da segunda edição do evento, conforme aponta o relato de Rodrigo de Farias (2016, p. 6):

No primeiro Seminário Urbanistas e Urbanismo no Brasil, realizado em 2013 na FAU-UnB, a problematização qualificativa ocorreu no confronto/oposição teórico-metodológica entre as ideias de 'Trajetória' e 'Biografia'; nesse segundo, realizado em 2015 no IAU-USP, a problematização esteve centrada nas trajetórias e interlocuções transatlânticas, sem aquele sentido interrogativo do primeiro. E foi justamente esta característica que abriu o caminho para certa provocação final (no bom sentido da provocação) ao próprio Seminário, ou seja, para apresentar outra proposta de análise, algo como outro caminho em relação aos temas e objetos do urbanismo no Brasil.

Como parte da estratégia de construção de uma narrativa que não escapasse ao eixo proposto, e reconhecendo meus próprios limites para formular uma análise ao mesmo tempo em grande angular e com as particularidades inerentes ao campo disciplinar do urbanismo e dos profissionais que atuaram nesse campo e no Brasil, um primeiro movimento que empreendi foi o de compilar algumas análises já realizadas sobre a pesquisa em história do urbanismo no Brasil. 
Conforme podemos observar no relato de Farias, o estudo das biografias responde a uma demanda específica: dar a ver a multiplicidade das ações individuais. Por outro lado, o estudo de séries de biografias acaba fazendo com que vislumbremos certos movimentos coletivos, que vão para além dos ajuizamentos individuais. Esse relato exemplifica, portanto, que, para interpretar os movimentos de um "saberfazer" - que se constrói e se modifica pelas ações individuais, mas que, ao mesmo tempo, constitui uma cultura, algo que se coletiviza -, é necessário manejar essas diferentes escalas.

No entanto, se nos parece evidente hoje que, para escrever qualquer história do urbanismo, é necessário o manejo dessas diferentes escalas, pode-se perguntar: por que há uma valorização da biografia na nossa historiografia recente?

\section{BIOGRAFIAS: UMA FORMA DE NARRATIVA CONTRA OS "MODElOS"}

Aqueles que se interessaram pela história do urbanismo, mas que traçaram seu percurso intelectual a partir do campo da história propriamente dito, já devem ter sido apresentados às críticas às abordagens estruturalistas, de fins dos anos 1960, que requalificaram a história política e os próprios indivíduos na história. É no interior desse movimento que a subjetividade reemerge como questão - para além dos estudos psicanalíticos, artísticos ou memoriais -, a tematização das culturas ganha maior complexidade e o próprio gênero literário biografia passa a ser redescoberto pelos historiadores.

Segundo François Dosse (2010), a biografia, que havia passado longos anos como um "gênero impuro" para a escrita acadêmica da história, passa a ser, então, redescoberta. É ele quem escreve:

Hoje, assistimos a uma inversão espetacular. O que era desvantagem ontem, tornou-se mesmo motivo de o sucesso. Trata-se desse caráter transversal [da biografia]. A biografia popular é mais exigente de um verdadeiro saber-controlar e os historiadores acadêmicos estão mais atentos às ondas individuais de sua disciplina. $\mathrm{O}$ resultado é uma aproximação entre a história 
e a biografia, a ponto de que aqueles que eram críticos [à biografia], seguindo Pierre Bourdieu, da 'ilusão biográfica', como [por exemplo] os adeptos da escola Annales, se tornaram autores de biografias impressionantes e notáveis como a de Saint Louis, publicada por Jacques Le Goff, em 1996. Em favor de uma virada pragmática e hermenêutica da disciplina histórica, a biografia foi retomada como um objeto de uma história acadêmica que se interroga sobre a ação humana dotada de sentido, intencionalidade, justificativas dos atores e traços memoriais. ${ }^{5}$ (DOSSE, 2010, p. 81-82, tradução nossa)

Se essa leitura historiográfica sublinha um panorama excessivamente francês, podemos dizer que as contribuições da micro-história italiana (GUINZBURG, 1991; LEVI, 2006; PORTELLI, 1989) e também da "história de baixo para cima", ${ }^{6}$ cunhada pelo inglês Edward Palmer Thompson (1966) e apropriada também por Eric Hobsbawn (1998), confirmam a tomada dessa mesma direção.

Contudo, se hoje observamos a história do urbanismo ser contaminada por essa onda de redescoberta dos indivíduos na história, não podemos dizer que essa matriz tenha sido a única ou principal nesse processo. Para falarmos sobre a revalorização do indivíduo nas narrativas sobre o urbanismo, é preciso remontar aos mesmos fins de anos 1960 e pensar que ele não vem "a reboque" de práticas de outro campo disciplinar, mas que compartilha (e também produz) um movimento de revisão epistemológica.

Para que essa hipótese se torne mais clara, podemos nos ater a dois trabalhos de Françoise Choay: L'Urbanisme, utopies et réalités: une anthologie (1965) e La règle et le modèle: sur la thèorie de l'architecture et de l'urbanisme (1980). Trata-se de livros em que a autora buscou sistematizar e interpretar os debates iniciais do urbanismo.

Publicado em 1965, L'Urbanisme, utopies et réalités, une anthologie é, ainda hoje, um livro reconhecido por seu caráter didático e amplamente utilizado nas escolas de arquitetura e urbanismo em todo o mundo. Essa boa recepção da obra da autora deve-se, em grande parte, à sistematização que ela elabora buscando identificar "modelos" que 
deram origem a disciplina, bem como as possibilidades de reflexão e ação sobre as cidades que não eram de origem modelar - este último, um aspecto pouco comum na bibliografia especializada sobre o tema, naqueles anos.

Os "modelos" eram, para a autora, espécies de arquétipos que alimentavam as propostas dos urbanistas ao longo de sua história, como, por exemplo, o culturalismo, o progressismo, o naturalismo. Seu trabalho de sistematização agrupou autores e ideias afins que haviam construído distintas "culturas urbanísticas", para utilizarmos um termo mais atual.

No entanto, neste olhar analítico e sistematizador elaborado por Choay, subjazia também uma crítica. Ao afirmar que o urbanismo era, em grande parte, de origem modelar, Choay denunciava que ele trabalhava por repetição de formas. Ou seja, ela expunha claramente seus limites.

Contudo, essa crítica de Choay não parece inviabilizar de todo a proposição de novas maneiras de se construir espaço, pois ela expõe também, mesmo que timidamente, que o urbanismo não é a única maneira. Mesmo que ele parecesse hegemônico nesta função, ao demonstrar que existiu um pré-urbanismo sem modelo ou que existia em seu tempo uma antrópolis, ela dava indicações desses outros caminhos.

Essa abertura na interpretação sobre o modo de construir espaço pode ser verificada também na escolha do gênero literário para elaboração do livro e a maneira como ela o apresenta. Ao decidir produzir uma antologia e, antes de cada texto, expor uma breve nota biográfica sobre o autor e o contexto de produção do texto a ser lido, Choay parece convidar o leitor a percorrer ele mesmo os caminhos que ela havia realizado, bem como a formular sua própria interpretação a partir do acesso às fontes.

Além desses aspectos da estrutura do texto, é importante destacar que, na época de sua publicação, a antologia de Choay representou outra forma de contribuição. Ela traduziu e fez circular textos estrangeiros Q 2 no ambiente francês justamente em um momento de crise propositiva 
e institucional do urbanismo. É Jean-Louis Violeau, tratando das pressões por mudanças no ensino de arquitetura nos anos 1960, na França, mais precisamente sobre a escassez de referências bibliográficas que dessem suporte a esse processo, quem melhor situa as contribuições de Choay no período. Referindo-se à bibliografia proposta para a entrada na École des Beaux Arts de Paris, em 1967, ele resume:

[...] Se confrontarmos [...] [a] demanda de 'Teoria' e de um ensino 'científico' vinda dos estudantes e jovens professores ao conselho [da Escola de Belas Artes] e as orientações bibliográficas anteriormente emitidos pela Direção dos estudos [...] [nesta instituição], a comparação é edificante: a 'Biblioteca d'Admissionista' distribuída, por exemplo, em março de 1967 pela administração da Escola não contém nenhuma obra de ciências humanas. [Ela] alinha uma série de referências cuja maioria foi publicada há mais de dez anos (Giedion, Sfaellos, Zevi), aconselha ainda uma obra de Gramont ('A arte dos jardins', os escritos fundadores de Le Corbusier ('Por uma arquitetura', 'A cidade radiosa' e 'O Modulor'), Ledoux e Paladio, a auto biografia de Wright e um conjunto de referências 'sensoriais' [como] escritos de pintores ou monografias [de artistas] (Klee, Mondrian, Picasso, Van Gogh, Delacroix, etc.).

A imaginação poética de Bachelard [...] ([em] 'A água e os Sonhos', 'O ar e os Sonhos' e especialmente 'A Poética do Espaço'), [bem como] [...] a 'Fenomenologia da Percepção' de Merleau-Ponty são esquecidos. Quanto a 'O homem vive como um poeta' e 'Construa, viva, pense', as duas conferências que Heidegger pronunciou em 1951, só se tornariam célebres junto aos arquitetos anos mais tarde. Não são mensionados nenhum trabalho de Levi-Strauss, nem ao menos de Roland Barthes, nem Henri Lefebvre, que já havia começado a trabalhar sobre a cidade. Os arquitetos ignoram ainda a maior parte dos trabalhos do ISU sobre a habitação operária e obra de Henri Coing, 'Renovação urbana e mudança social', que também aparece, em 1966, em Payot. Neste ano de 1967, Anatole Kopp publica 'Cidade e Revolução' e Roger-Henri Guerrand [publica] 'As origens da habitação social', obras 
conhecidas apenas em pequenos círculos, como também a antologia de textos reunidos por Françoise Choay. Uma antologia que também terá um sucesso considerável porque responde precisamente à necessidade de 'teoria' e referências em um ambiente onde as traduções são quase inexistentes. ${ }^{\text {? }}$ (VIOLEAU, 2005, p. 123, tradução nossa)

O momento descrito por Violeau (2005) era de grande pressão para reformulação do ensino de arquitetura e declínio de prestígio do próprio ensino de urbanismo. (LILLE, 2005) Tratava-se de uma crise deflagrada, sobretudo, pelo fracasso dos "conjuntos habitacionais" e o esvaziamento dos antigos centros urbanos. Alguns autores, notadamente do círculo próximo a Henri Lefebvre, denunciavam também a falência da própria figura do urbanista.

De fato, nesse período na França, a atuação do urbanista, seja aquele que se interessava pelas cidades a partir dos estudos de arquitetura, seja do urbanismo propriamente dito, encontrava uma teoria balizada pelas proposições dos Congressos Internacioanais de Arquitetura Moderna (CIAM) e de Le Corbusier, que haviam guiado a prática da disciplina de forma quase hegemônica desde a década de 1920, mas que não subsidiavam mais o enfrentamento dos problemas aqui descritos.

Assim, a antologia de Choay, além de situar o percurso de uma tradição em eminente falência e, com isso, mostrar onde residiam seus limites, trazia também experiências passadas e contemporâneas que, distante da França, pareciam instaurar novas formas de construção do espaço. Ou seja, fazia uma espécie de voto à renovação teórica da disciplina, como reclamada pelos alunos e jovens professores à época. (VIOLEAU, 2005, p. 123)

La règle et le modèle, sur la thèorie de l'architecture et de l'urbanisme foi publicado 15 anos após a antologia e sua produção exigiu um fôlego muito maior da autora. Esse livro é o resultado de uma thèse d'État defendida no departamento de Letras da Universidade de Nanterre, 8 4 sob a orientação de Mikel Dufrenne, em 1978. (CHOAY, 1978) 
Os resultados parciais da elaboração de La règle et le modèle já eram sentidos em pequenos artigos publicados em um periódico de grande circulação, a Quinzaine Literaire, entre fins da década de 1960 e começo da década de 1970. No entanto, a questão central de sua tese, a oposição entre duas tradições discursivas de textos instauradores de espaço - a utopia e a tratadística -, aparece claramente enunciada em uma apresentação de um colóquio organizado pelo Institut de l'Environnement, em 1972. (CHOAY, 1974, p. 151-183) Como se pode perceber, tratou-se de um esforço de síntese intelectual construído ao longo de, pelo menos, dez anos.

Em relação ao livro precedente, Choay mantém o interesse pela digressão histórica para pensar o problema da produção dos assentamentos humanos, e ela se mantém fiel também ao estudo dessa prática a partir de sua forma textual. Ainda em relação ao livro precedente, ela reafirma sua hipótese de que o urbanismo, da maneira como está sendo praticado em sua época, é de origem modelar e utópica.

No entanto, uma série de posições é alterada entre um livro e outro. Em La règle et le modèle, o arco temporal analisado pela autora recua ao século XVI e não se circunscreve apenas ao urbanismo. Ela se aproxima da literatura e da antropologia e amplia de fato seu objeto de estudo para os discursos instauradores de espaço, nos quais o urbanismo é apresentado apenas como uma de suas modalidades, que toma forma a partir da Revolução Industrial. Assim, sua busca por uma prática de construir cidades longe dos modelos não aparece mais timidamente, pois ela encontra na tradição dos artistas e arquitetos do Renascimento um modo a pensar esse processo de engendramento de formas materiais e imateriais. Ou seja, um modo de instaurar o novo, aquilo que pede atualização ou ainda não pode ser formulado.

Ao apresentar esses dois trabalhos desenvolvidos por Choay, gostaríamos de sublinhar dois aspectos operados pela autora: primeiramente, ela identifica o impasse vivido pelo urbanismo nos anos 1960, uma crise de proposição desencadeada por um modo operativo baseado em modelos. Em seguida, ela propõe uma alternativa para desarmar esse aparente "ciclo vicioso" do pensar por modelos. Apresentando os autores (urbanistas) e suas ideias, Choay explicita que proposições 
reagem a situações especificas, são interpretações realizadas por um indivíduo diante de uma questão. Por conseguinte, identifica que, ao se generalizar uma solução ou ao adotar uma solução que se propõe genérica, silenciam-se autores e situações. Esse duplo problema tem como resultado a morte do próprio urbanismo, entendido em seu viés "científico" como ele vinha sendo considerado até então.

Voltando a nossa discussão inicial - os usos da biografia nas narrativas sobre o urbanismo - e contrapondo à operação desencadeada por Choay, pode-se concluir que a escrita biográfica ${ }^{8}$ vem acompanhada de uma crítica ao urbanismo que é operado por repetição de modelos; portanto, uma reação a interpretações do urbanismo de modo genérico e a-situado.

BiografiaS: UMA FORMA DE SE CONSTRUIR "HISTÓRIA DE BAIXO PARA CIMA"

Acredita-se, aqui, que o problema que Choay busca enfrentar nas suas publicações de 1965 e 1980 é ainda hoje atual. É curioso notar, por exemplo, que em um recente encontro da International Planning History Society (IPHS), em 2012, a conferência de abertura tenha tido como título "Cities as Planning Models". Mais curioso ainda é observar que essa exposição pouco polemiza o estatuto do modelo enquanto difusor de práticas. Stephen Ward (2012, p. 22-23, tradução nossa) resume sua conferência:

Ao longo da história do planejamento moderno, uma característica chave tem sido a importância das cidades 'modelo', lugares específicos amplamente admirados por seu perceptivel 'bom planejamento'. Elas têm sido cidades que inspiraram e informaram outras, nascidas tanto no mesmo país quanto em outros. Em graus variados, elas estimularam a emulação, o empréstimo seletivo ou parcial e até mesmo a cópia direta de seus admirados recursos de planejamento [...].

Esta palestra explorará esse fenômeno das cidades como modelos de planejamento. Destacará algumas cidades que planejaram modelos em diferentes momentos e em diferentes regiões do mundo. Também considerará o processo de como eles se tornaram ou estão se tornando modelos. Isto envolverá a análise dos métodos pelos quais o conhecimento e a reputação 
do 'modelo' foram e são disseminados e adquiridos. [...]

Em geral, a palestra identificará uma importante área para os historiadores do planejamento investigarem. Uma área que tenha dimensões tanto específicas quanto genéricas. É também um fenômeno que permanece como uma característica chave e, possivelmente, um recurso de fortalecimento na circulação do conhecimento do planejamento contemporâneo. A palestra não responderá a todas as questões circundantes [ao tema, não será dado um nem] sentido final, [nem um sentido] definitivo [para o termo], mas se pretende abrir novos debates e estimular os historiadores e comentadores do planejamento. ${ }^{9}$

Aqui, a reflexão fomentada nos trabalhos de Choay, em que o pensar por biografias é uma parte constitutiva, desaparece. Nas palavras de Ward, não só o termo "modelo" se desprende de sua historicidade e dos sentidos que ganhou na nossa história recente, como também passa a estar cristalizado nas formas materiais das cidades. Destituindo-as das práticas urbanísticas que as engendraram, dos seus "lugares de enunciação", das situações e motivos que fizeram com que seu(s) autor(es) decidisse(m) por uma solução e não por tantas outras. Afinal, uma Paris, uma Nova York ou um Rio de Janeiro de hoje não são resultados do gesto de um único ator social, muito menos de um gesto realizado em um único ato (tempo).

Desconhecer ou silenciar esses aspectos das produções urbanísticas resulta, portanto, no mesmo problema já enunciado pela autora: empobrecer o urbanismo e o aleijar de sua capacidade de inventar novas práticas, novos futuros e de ser crítico à vida presente. Em outras palavras, impede o urbanismo de ser verdadeiramente histórico.

Assim, diante do problema da difusão de modelos e da alienação dos discursos do urbanismo, pensar por biografias pode ser um convite a uma abordagem que o historiador inglês Edward Palmer Thompson chamou de "história de baixo para cima", ou uma história que refuta as categorias pré-estabelecidas e as análises da longa duração para construir a interpretação histórica a partir da análise dos próprios atores sociais e suas práticas. 
Trata-se de uma abordagem já sublinhada em trabalhos como aqueles de Michel de Certeau $(1975,1982)$ sobre a noção de "operação historiográfica”, mas que será certamente mais valorizado com a história cultural realizada por Roger Chartier. Nela, a atenção aos atores sociais e suas práticas ganha uma maior complexidade. Ao se centrar nas noções de "prática" e de "representação", ele incita a construção da narrativa histórica sobre o mundo social entre aquilo que limita a ação dos atores, "suas condições de possibilidade", e os caminhos que eles inventam e/ou por onde eles escapam dos sentidos hegemônicos. (CHARTIER, 2009, p. 11-12)

No entanto, neste ponto, é necessário explicitar ainda outro aspecto do convite expresso pelo pensar por biografias. Trata-se da valorização da curta duração e da profundidade que a análise centrada na trajetória de um único indivíduo pode revelar sobre um tema.

François Dosse (2005), em Le pari biographique: écrire une vie, se detém à biografia enquanto gênero narrativo da história, desdobrando as reflexões de Certeau. Para ele, a biografia possibilita uma espécie de jogo entre várias escalas de análise, pois mantém um olhar atento às especificidades dos gestos individuais sem apartar o indivíduo biografado de sua rede de sociabilidade e das suas condicionantes sociais e/ou culturais.

Mais especificamente em relação à "biografia intelectual”, Dosse (2005) nos traz ainda mais insumos para se estruturar essa reflexão. Para ele, esse tipo de biografia busca realizar uma leitura transversal entre vida e a produção intelectual. É nesse processo de fricção do relato das experiências vividas pelo biografado com a leitura de sua obra que o historiador formula questões. Ou seja, ele dá forma à "intriga”, nas palavras de Paul Ricoeur. Nesse processo, o historiador, ao mesmo tempo, flerta e se afasta dos perigos da "ilusão biográfica", alertada por Pierre Bourdieu, pois ele se esquiva da tarefa inexequível de dar sentido a todos os gestos do percurso de um indivíduo e passa se engajar (apenas) na formulação de hipóteses, na construção de um conjunto especifico de interpretações.

Deve-se mencionar ainda o trabalho recente de Sabina Loriga (2011), 8 8 O pequeno X: da biografia à história. Ao explorar um conjunto de 
autores que se estende de Burkardt à Tolstoi, passando por William James, Max Weber, Walter Benjamin e Siegfried Kracauer, a autora resume de maneira elucidativa que a criatividade dos indivíduos não é um princípio absoluto, "ela procede da ação recíproca entre os indivíduos". Ao mesmo tempo, lembra-nos que a sociedade, como totalidade social, não é independente, nem uma estrutura superior aos indivíduos. Ela justamente é uma obra que se estabelece no jogo entre as dimensões individual e coletiva. Além disso, seu livro nos ajuda a lembrar que a história, enquanto narrativa, não precisa uniformizar o passado, visto que ele é mesmo de natureza multiforme e aberta. $^{10}$ (LORIGA, 2011, p. 16)

Por fim, pode-se lembrar que a biografia, como uma abordagem para a história do urbanismo, se beneficia dos estudos antropológicos, que entendem que um saber-fazer - o urbanismo é um saber-fazer - é produto de culturas. Nessa condição, o urbanismo é estabelecido a partir do conjunto de práticas individuais que, no jogo do cotidiano, são coletivizadas e ressignificadas. Isso nos permite afirmar que a produção de um urbanista é, ao mesmo tempo, fragmento de um percurso pessoal, mas também sintoma de mudanças no próprio campo epistemológico e produtora de sua reformulação.

\section{BIOGRAFIAS: PARA ATRAVESSAR FRONTEIRAS E ATIVAR O PASSADO}

Dois importantes seminários realizados no Brasil, o SHCU e o SUUB, separados 20 anos no tempo, nos ajudaram a mapear como a escrita da história do urbanismo vem se delineando e como, apesar do aumento de interesse pela escrita biográfica hoje, ela não significa a preponderância deste gênero sobre os demais.

A comparação dos artigos desses dois seminários nos possibilitou perceber que a escrita da história parece uma sucessão de pranchas de arquitetura, na qual diferentes escalas são manipuladas para construir a obra. $\mathrm{O}$ autor-arquiteto, para compor o texto-projeto, precisa ora se aproximar, ora se afastar de seu objeto de estudo, para obter dele diferentes pontos de vista; ou seja, para interpretá-lo. 
No entanto, mesmo sabendo disso, coube ainda pergunta: por que insistir em tomar em consideração os aspectos fugazes da existência, a curta-duração, ou a vida de um único indivíduo? Por que escrever um "pensar por biografias"?

Ao longo do presente artigo, buscou-se demonstrar como trabalhos de historiadores como Dosse e Loriga apresentam com clareza os sentidos que a escrita biográfica têm adquirido na contemporaneidade. No entanto, visou-se enfatizar também como, no urbanismo, os trabalhos de Françoise Choay trouxeram contribuições para a questão. Neles, as biografias são um recurso importante não só para revelar diferentes culturas urbanísticas, como também para desconstruir uma historiografia e uma prática profissional pautadas por modelos. $\mathrm{Ou}$ seja, desconstruir os a priori que parecem assombrar a vivacidade do urbanismo desde os anos 1960.

Assim, a ênfase dada ao "pensar por biografias" aqui procura apresentar a importância de se narrar urbanismo de modo situado e atento aos diferentes sentidos que esse saber-fazer pode ter para indivíduos e suas culturas. Portanto, ela procura romper modelos, atravessar fronteiras e ativar o passado. 


\section{NOTAS}

1 Agradecimentos: este trabalho se beneficia diretamente dos debates promovidos pelos ciclos de historiografia do Laboratório de Estudos Urbanos do Programa de Pós-Graduação em Urbanismo (PROURB) da Faculdade de Arquitetura e Urbanismo da Universidade Federal do Rio de Janeiro (FAU-UFRJ), especialmente ao diálogo com os colegas de laboratório Mário Magalhães e Daniela Ortiz dos Santos. Agradecemos também pelas contribuições e críticas de Guilherme Meirelles e Marcela Giraldo, colegas de doutorado no PROURB/FAU/UFRJ, e a revisão realizada pela professora doutora Margareth da Silva Pereira, nossa orientadora de doutorado.

2 Pode parecer curioso, mas esta edição do SHCU dedica-se realmente a discutir o objeto da "história urbana" e não da "história do urbanismo", que dá nome ao próprio seminário.

3 Vale ressaltar que não estamos apontando para a necessidade de pensar o urbanismo como um saber "de especialistas" ou de um "ramo profissional". Como já apontamos de início, entende-se o urbanismo como uma cultura que interroga, interpreta e projeta as diferentes dimensões da vida em cidades. Contudo, o aspecto que se salienta é o silenciamento de sua especificidade.

4 A noção de "temporalidades" vem sofrendo diferentes leituras ao longo dos últimos 50 anos. Em "Gestos urbanos: pensar o tempo", Margareth Pereira (2017) realizou um balanço historiográfico aprofundado sobre o tema, que aqui aparece apenas de maneira tópica.

5 “Aujourd'hui, l'on assiste à um renversement spectaculair. Ce qui était handicap hier. Devient raison même du succès, soit ce caractere transversal. La biographie populaire est plus exigeante d'un véritable savoir contrôlé et les historiens savants sont plus attentifs aux ondes individuées de leur discipline. Il en resulte un rapprochement entre histoire et biographie au point que ceuxlà mêmes qui se sont fait les dénonciateurs, à la suíte de Pierre Bourdieu, de 'l'illusion biographique' comme les tenants de l'ecole des Annales se sont fait les auteurs d'imposantes et remarquables biographies comme celle de Saint Louis publiées par Jacques Le Goff en 1996. À la faveur du tournant pragmatique et hermeneutique de la discipline historique, la biographie a fait retour em tant qu'objet de l'histoire savante s'interrogeant sur l'action humaine dotée de sens, l'intentionnalité, la justification des acteurs, les traces mémorielles".

6 Tradução nossa para "history from below". 
7 “[...] Si l'on confronte [...] [la] demande de 'Theorie' et d'un enseignement 'scientifique' émanant des étudiants et des jeunes enseignants aux conseils et orientations bibliographiques auparavants délivrés par la Direction des études aux Beaux-Arts, la comparaison est édifiant : la 'Bibliothèque de l'admissioniste' distribuée, par exemple, em mars 1967 par l'administration de l'École ne contient aucun ouvrage en sciences humaines, aligne une suite de références parues pour la plupart depuis plus de 10 ans (Giedion, Sfaellos, Zevi), conseille encore un ouvrage de Gramont (L'art des jardins), les écrits fondateurs de Le Corbusier (Vers une architecture, La ville radieuse et Le Modulor), Ledoux et Palladio, l'autobiographie de Wright, et une kyrelle de références 'sensibles', des écrits de peintres ou de monographies (Klee, Mondrian, Picasso, Van Gogh, Delacroix...). L'imagination poétique de Bachelard et tout un pan du travail du philosophe (L'Eau et les rêves, L'Air et les Songes, et surtout La Poétique de l'espace) ainsi que la Phénoménologie de la perception de Merleau-Ponty sont oubliés. Quand à 'L'Homme habite en poète'et 'Bâtir, habiter, penser', le deux conférences qu'Heidegger prononça en 1951, elle ne seront célèbres chez les architectes que bien plus tard. On ne mentionne aucun ouvrage de Lévi-Strauss, encore moin de Roland Barthes, ni d'Henri Lefebvre qui a pourtant déjà commencé à travailler sur la ville. Les architectes ignorent encore pour la plupart les travaux de l'ISU sur l'habitat pavillonnaire. L'ouvrage d'Henri Coing, 'Renovation urbaine et changement social', qui paraît lui aussi en 1966 chez Payot. En cette année 1967, Anatole Kopp publie 'Ville et Revolution' et Roger-Henri Guerrand, 'Les origines du Logement Social', ouvrages qui ne sont alors connus que de petits circles, tout comme l'anthologie de textes ressemblés par Françoise Choay. Une anthologie qui devra aussi son succès considerable au fait qu'elle répond précisement au besoin de 'théorie'et de références d'un milieu où les traductions sont quasiment inexistentes".

8 É importante ressaltar que Françoise Choay não é uma biógrafa propriamente dita. Marcada pelo estruturalismo dos anos 1960, em seus trabalhos, muitas vezes, desencorajou os estudos biográficos. No entanto, sua prática narrativa afirma uma atenção aos atores e seus discursos, aspecto que posteriormente seria reconhecido como "biografias intelectuais". É justamente esse último aspecto que nos interessa aqui.

9 "Throughout modern planning history, a key feature has been the importance of 'model' cities, specific places widely admired for their perceived 'good planning'. They have been the cities that have inspired and informed others, both in the same country and in others. In varying degrees, they have stimulated emulation, selective or partial borrowing, even direct copying of their admired planning features [...].

92 will highlight some cities which have been planning models at different times 
and in different world regions. It will also consider the process of how they became or are becoming models. This will involve examining the methods by which the knowledge and reputation of the 'model' has been and are disseminated and acquired [...].

Overall the lecture will identify an important area for planning historians to investigate, one that has both specific and generic dimensions. It is also a phenomenon that remains also a key and, arguably, a strengthening feature in the circulation of contemporary planning knowledge. The lecture will not answer all the surrounding questions in any final or definitive sense but it aims to open up new debates and stimulate historians of and commentators on planning".

10 Os aspectos que Loriga sintetizou recentemente de maneira elucidativa são os mesmos que estão na estruturação base do projeto Cronologia do Pensamento Urbanístico (http://www.cronologiadourbanismo.ufba.br/) e do conceito de nebulosas de Pereira (2007) e Topalov (1999), desenvolvidos ambos há longa data. 


\section{REFERE N CI $\Lambda S$}

APRESENTAÇÃO. XIV Seminário de história da cidade e do urbanismo. São Carlos, 2016. Disponivel em: <http://www.iau.usp.br/ shcu2016/?page_id=2>. Acesso em: 29 out. 2017.

APRESENTAÇÃO: Informe I. I Seminário Urbanistas e Urbanismo no Brasil. Brasília, DF, 2013. Disponível em: <http://trajetorias-urbanistas. blogspot.com.br/2011/12/apresentacao-do-seminario-informe-i. html?view=sidebar>. Acesso em: 29 out. 2014.

BRAUDEL, F. Escritos sobre história. São Paulo: Perspectiva, 2009.

BRESCIANI, M. S. Permanência e ruptura no estudo das cidades. In: FERNANDES, A.; GOMES, M. A. F. (Org.). Cidades $\mathcal{E}$ historia: modernizacao das cidades brasileiras nos seculos XIX E XX. 1. ed. Salvador: UFBA, 1992. p. 11-26. Disponível em: <http://www.anpur.org.br/ revista/rbeur/index.php/shcu/issue/view/29>. Acesso em: 21 set. 2014.

CALABI, D. Marcel Poëte et le Paris des années vingt: aux origines de "l'histoire des villes". Paris: L'Harmattan, 1997.

CERTEAU, M. L'écriture de l'histoire. Paris: Gallimard, 1975.

CERTEAU, M. L'opération historique. In: LE GOFF, J.; NORA, P. (Ed.). Faire de l'histoire. Paris: Gallimard, 1974. p. 3-41.

CHARTIER, R. Au bord de la falaise: l'histoire entre certitudes et inquietudes. Paris: Albin Michel, 2009.

CHOAY, F. La cité du désir et la ville modèle: essai sur l'instauration textuelle de la ville. 1978. Thèse (Doctorat en Philosophie) - Université de Paris X, Paris, 1978.

CHOAY, F. L'urbanisme, utopies et réalités: une anthologie. Paris: Seuil, 1965.

CHOAY, F. Notes Preliminaires a une semiologie du discours sur la ville. Notes metodologiques en architecture et en urbanisme (3/4). Centre de Mathématiques, Méthodologie, Informatique; Institut de 9 4 l'Environnement, janv. 1974. p. 151-183. 
CHOAY, F. La règle et le modèle: sur la théorie de l'architecture et de l'urbanisme. Paris: Seuil, 1980.

DE LILLE, L. C.; BUSQUET, G.; CARRIOU, C. Un ancien institut... Créteil: Paris XII/IUP, 2005.

DOSSE, F. Biographie, prosopographie. In: DELACROIX, C. et al. Historiographies, I: Concepts et débats. Paris: Gallimard, 2010. p. 79-85.

DOSSE, F. Le pari biographique: Écrire une vie. Paris: La Découverte, 2005.

FARIA, R. O urbanismo e os urbanistas na história urbana brasileira: percursos e perguntas para pensar a história urbana da América Latina. Risco, São Carlos, v. 14, n. 2, p. 6-14, 2016.

FARIA, R.; CERASOLI, J. Editorial: urbanistas e urbanismo no Brasil. Urbana, Campinas, v. 5, n. 7, p. 1-4, 2013. Disponível em: <https:// periodicos.sbu.unicamp.br/ojs/index.php/urbana/issue/view/304/ showToc>. Acesso em: 14 out. 2017.

GUINZBURG, C. et al. A micro-história e outros ensaios. Viseu: Tipografia Guerra, 1991. (Original de 1989).

HOBSBAWN, E. A história de baixo para cima. In: HOBSBAWN, E. Sobre história. São Paulo: Companhia das Letras, 1998. p. 216-232. (Original de capítulo em 1985 e do livro 1997).

LEPETIT, B. Sobre a escala na história. In: REVEL, J. (Org.). Jogos de escala: a experiência da microanálise. Rio de Janeiro: FGV, 1998. p. 77-102. (Original de 1996).

LEVI, G. Usos da biografia. In: FERREIRA, M.; AMADO, J. Usos e abusos da história oral. Rio de Janeiro: FGV, 2006. p. 167-182. (Original de 1989).

LORIGA, S. O pequeno X: da biografia à história. Belo Horizonte: autentica, 2011.

PEREIRA, M. Las Nebulosas In: URQUIZO, W. L. Enfoques historiográficos conteporáneos. Bogotá: Universidad Nacional de Colombia, Faculdad de Artes, 2007. (Documentos de historia y teoria, 16). 
PEREIRA, M. Inocência e reflexividade: ou notas sobre as construções narrativas da história da arquitetura e do urbanismo. In: BERENSTEIN, P.; BRITO, F. (Org.). Experiências metodológicas para compreensão da complexidade da cidade contemporânea: memória, narração e história. Salvador: EDUFBA, 2015. p. 17-46. VI. Memória narração história. Disponível em: <http://www.laboratoriourbano.ufba.br/pronem/ ColecaoTomoIV.pdf〉. Acesso em: 10 nov. 2017.

PEREIRA, M. Gestos Urbanos: pensar o tempo. In: BRITO, F.; BERENSTEIN, P. (Org.). Corpocidade: gestos urbanos. Salvador: EDUFBA, 2017. p. 150-171. Disponível em: <https://issuu.com/ laboratoriourbano/docs/000>. Acesso em: 10 nov. 2017.

PORTELLI, A. Historia y memoria: la muerte de Luigi Trastulli. Historia y Fuente Oral, Barcelona, n. 1, p. 5-32, 1989.

REVEL, J. (Org.). Jogos de escala: a experiência da microanálise. Rio de Janeiro: FGV, 1998.

ROLNIK, R. História urbana: história na cidade? In: SEMINÁRIO DE HISTÓRIA DA CIDADE E DO URBANISMO, 1993, São Paulo. Anais... São Paulo: [s.n.], 1993. v. 2, p. 27-29. Disponível em: <http:// www.anpur.org.br/revista/rbeur/index.php/shcu/issue/view/29>. Acesso em: 21 set. 2014.

SANTOS, M. A cidade e o urbano como espaço-tempo. In: SEMINÁRIO DE HISTÓRIA DAS CIDADES E DO URBANISMO, 1993, São Paulo. Anais... São Paulo: [s.n.], 1993. v. 2, p. 242-243. Disponível em: <http:// www.anpur.org.br/revista/rbeur/index.php/shcu/issue/view/29>. Acesso em: 21 set. 2014.

TOPALOV, C. La nébuleuse réformatrice et ses réseaux en France, 1880-1914. Paris: Éd. de l'EHESS, 1999.

THOMPSON, E. P. History from Below. Times Literary Supplement, London, p. 279-280, Apr. 1966.

9 G VIOLEAU, J.-L. Les architectes et Mai 68. Paris: Éditions Recherches, 2005. 
WARD, S. V. Cities as Planning Models. In: 15TH IPHS Conference: cities, nations \& regions in planning history, São Paulo, Brazil, $15-18$ july 2012: book of abstracts. [S.l.: s.n.], 2012. p. 22-23. 